\title{
VIEWPOINT
}

\section{Racial Privilege and Medical Student Awards: Addressing Racial Disparities in Alpha Omega Alpha Honor Society Membership}

\author{
Dowin Boatright, $M D, M B A, M H S^{7}$, Patrick G. O'Connor, $M D, M P H^{2}$, and Jennifer E. Miller, \\ $P h D^{2}$
}

'Department of Emergency Medicine, Yale School of Medicine, New Haven, CT, USA; ${ }^{2}$ Department of Internal Medicine, Yale School of Medicine, New Haven, CT, USA.

$\mathrm{J}$ Gen Intern Med 35(11):3348-51

DOI: $10.1007 / \mathrm{s} 11606-020-06161-\mathrm{x}$

(c) Society of General Internal Medicine 2020

\section{INTRODUCTION}

Racial/ethnic disparities in the receipt of awards among physicians have been widely reported in academic medicine. ${ }^{1-4}$ Now we have evidence showing similar disparities for medical students as well, as a recent study found Black and Asian medical students are less likely than White students to be elected to the prestigious Alpha Omega Alpha (AOA) honor society. ${ }^{5}$

AOA membership aims to signal exceptional academic performance. However, it may be based on a meritocracy myth ${ }^{6}$ in some circumstances, as getting into and succeeding in medical school can be more challenging for students of color, due to social barriers and biases. ${ }^{7}$ Consequently, AOA, may be perpetuating - or worse, compounding - demographic privilege.

Although each AOA chapter has specific criteria for the selection of members, individual AOA chapters must adhere to at least two guidelines designated by the national AOA society: (1) only students ranking in the highest quartile by academic performance are eligible for honor society membership and (2) each chapter can select only up to $16 \%$ of medical students as AOA members. An AOA committee, at the level of the individual medical school, determines which medical students will ultimately be inducted. ${ }^{8}$

Membership helps students access the most competitive residency programs and promotes career advancement. Yet, the organization's benefits accrue disproportionately to White students. Because of the importance placed on AOA membership, racial/ethnic membership imbalances could represent a form of structural racism and have profound implications for students, patients, medical research, and the diversity of the

Received February 26, 2020

Accepted August 14, 2020

Published online August 31, 2020 healthcare workforce. To help address this problem, we propose a series of reforms.

\section{CONSEQUENCES OF RACIAL IMBALANCE} Impact on Medical Students

AOA membership advantages medical students most directly by helping them match into their preferred specialty for residency training. ${ }^{9}$ Although only $16 \%$ of medical school graduates, AOA members comprise $40 \%$ of new trainees in the competitive fields of dermatology, plastic surgery, orthopedic surgery, urology, radiation oncology, and otolaryngology. ${ }^{9}$ AOA membership improves an applicant's likelihood to match into these competitive specialties ${ }^{10}$ and also their likelihood of matching into primary care fields, even among applicants scoring in the highest quintile on the USMLE Step 1 exam. $^{11}$

A prestigious residency can provide a lifetime of easier upward mobility for physicians, positioning them for esteemed fellowships and ultimately faculty positions. Members also gain exclusive access to chapter activities across the USA, affording grant funding as well as networking and mentorship opportunities, which can mean the difference between a successful and unsuccessful career and staying or leaving the profession. ${ }^{12}$ Additionally, AOA membership can confer financial benefit as the most competitive medical specialties often have the highest salaries. This difference in potential future earnings is important because prior work has shown that some racial/ethnic groups historically underrepresented in medicine bear disproportionately high debt burdens compared to their peers. ${ }^{13}$

\section{Impact on Patient Care}

Limiting opportunities for medical students of color does not just hurt students, it adversely impacts patient care. Physician workforce diversity is associated with better patient-centered care, healthcare access, and patient outcomes. ${ }^{14}$ The National Academy of Medicine identified increasing healthcare workforce diversity as an essential intervention to eliminate racial/ ethnic disparities in healthcare quality and access. ${ }^{15}$ 


\section{Impact on Academic Medicine}

Black, Hispanic, and Native American physicians comprise just $7.3 \%$ of faculty in academic medicine. While multiple factors are responsible for this underrepresentation, it cannot be ignored that AOA members are more likely to enter academic medicine and more likely to attain the rank of dean, full professor, and department chair than non-members. ${ }^{5}$ Faculty of color offer numerous benefits to the educational environment. Underrepresentation of racial/ethnic minority faculty in academic medicine has the potential to impact mentorship opportunities for minority medical students ${ }^{16}$ and trainees, ${ }^{17}$ the curricular content in medical education, ${ }^{18}$ and the national research agenda. ${ }^{19,20,21}$

\section{SUGGESTED REFORMS}

\section{National AOA Society-Level Reforms}

The national AOA society has expressed a commitment to support diversity, inclusion, and equity in medical schools. ${ }^{22}$ Moreover, the AOA constitution states, "No candidate shall be denied election because of race, color, creed, ethnic origin, age, or gender." ${ }^{22}$ Nevertheless, the authors are unaware of efforts by the national AOA society to systematically address racial/ethnic disparities among its members. Thus, we propose three reforms.

First, we recommend the national society to consider annually reporting aggregate statistics on a variety of member demographics including race/ethnicity, gender, first-generation college graduate status, disability, and sexual orientation for newly elected members, both in aggregate and by school chapter, on its website in an easily accessible location. Several medical associations, including the Association of American Medical Colleges, already report student demographic data. Social reporting can be an effective instrument to improve transparency, accountability, and even behaviors by institutions subject to reporting, particularly when a third-party intermediary is involved in the reporting. ${ }^{23,} 24$

Second, the national society could develop transparent criterion-based metrics for selecting members, to provide standardization and transparency while mitigating the potential for bias. Criterion might include automatic selection for students in good academic standing that have held a national or regional leadership office, presented or published peer-reviewed research, and completed a threshold number of community service hours. Alternatively, the society could consider closing the gap allowing for selection subjectivity (the gap between the $25 \%$ of students who qualify for membership and the $16 \%$ elected). Perhaps only the top $16 \%$ of students should qualify and be automatically elected.

Third, the national society could ensure its own leadership contains sufficient diversity encompassing gender diversity, racial/ethnic diversity, diversity by sexual orientation, socioeconomic status, and disability status. Diversity is essential for reducing risks of implicit bias and providing positive role models to current and future students. ${ }^{25,26}$

\section{Reforms for AOA Chapters}

In the absence of action from the national organization, medical schools have an ethical obligation to take responsibility for their chapters and lead reform efforts. The following actions may help.

First, local AOA chapters could review the composition of their newly elected cohorts for racial/ethnic disparities, at a minimum assessing whether members appropriately represent their medical student body demographics. Medical schools could include in their Medical Student Performance Evaluations (MSPEs) a brief section reporting the medical school student body compositional diversity overall by race/ethnicity and the corresponding compositional diversity of AOA members. Findings from these reviews could be easily accessible and included in the MSPE submitted with student applications to residency programs.

Second, we suggest that medical schools with racial/ethnic differences in AOA membership consider conducting a root cause analysis of this disparity. Racial/ethnic disparities in AOA membership could indicate differential treatment of medical students by race/ethnicity that is pervasive throughout the institution. This type of investigation was recently completed by the University of California, San Francisco School of Medicine (UCSF), which found that racial/ethnic minority medical students were not only historically less likely than White students to be selected as AOA members, but that racial/ethnic minority students were less likely to receive ratings of honors on their clinical clerkship performance evaluations. ${ }^{27}$ Similar studies have shown that racial/ethnic minority medical students are described less favorably than their White peers in the written comments on performance evaluations, even when controlling for standardized measures of academic performance. ${ }^{28-30}$

Third, chapters could ensure their leadership is appropriately diverse to reduce bias when choosing and mentoring members. We also recommend inviting the institutions' Chief Diversity Officer to serve on the chapter's leadership board. In the event that a local AOA chapter's medical school does not have a chief diversity officer, we recommend AOA chapters to at least identify a "diversity advocate" to serve as a selection committee member.

Fourth, local AOA chapters could use holistic review to select members. Prior literature shows a strong association between honor society membership and USMLE step 1 scores. ${ }^{5}$ Nevertheless, prior study findings demonstrate no correlation between AOA membership and hours dedicated to community service, leadership activity, or research productivity. ${ }^{5}$ This suggests an overreliance on standardized test scores by local AOA chapters despite guidance from the national AOA society to use a holistic 
process to select members. Consequently, we recommend that local chapters develop a mission-driven, holistic assessment when evaluating students for membership that more closely reflects the values of professionalism, leadership, and community service espoused by the national AOA society. Holistic review was recently adopted by UCSF's AOA chapter, which has since seen a significant reduction in racial/ethnic disparities among students selected for honor society membership. ${ }^{31}$

Fifth, chapters could consider electing members only in the last year of medical school after the residency match has occurred. While this intervention does not address the racial/ ethnic imbalances in membership, it will mitigate the immediate downstream impact of AOA racial/ethnic disparities on residency match outcomes.

Finally, medical schools could collectively suspend new student elections until they have taken the steps outlined or are satisfied sufficient action has been taken on the national level. Chapters could continue providing student scholarships during the suspension by expanding the applicant pool to include all members of the school's medical student community. Until reforms have been implemented to eliminate racial disparities in membership, it is possible that student selection into AOA will represent a structural barrier to diversity, equity, and inclusion in medicine. In 2018, Mount Sinai stopped AOA student elections after recognizing that Black and Hispanic/Latinx students constituted just $4 \%$ of its AOA members despite comprising $18 \%$ of the total student body. ${ }^{32}$

\section{Reforms for Intuitions Serving Graduate Medical Education}

Other groups can and could play a role in ameliorating racial/ ethnic disparities in AOA membership. For instance, the leadership of the Electronic Residency Application Service (ERAS) could stop integrating AOA status into the standard residency application, until racial/ethnic inequalities have been demonstrably remedied nationally. The incorporation of AOA status as a standard component of the ERAS application could amplify racial disparities in graduate medical education and enable the honor society to function as a structural barrier limiting physician workforce diversity.

Additionally, given prior study findings, ${ }^{5}$ residency program directors could give measured consideration to AOA status when screening applicants, until remedial action has been taken on a national level. As the number of applications to residency programs continues to grow, program directors understandably must rely on filters to triage applicants. Nevertheless, a screening process dominated by AOA membership could limit opportunities for minority candidates, who may have already encountered structural barriers and biases in applying, qualifying, and being selected for graduate medical education.

\section{CONCLUSIONS}

Given the benefits of AOA membership, it is unethical to ignore its racial disparities. AOA represents a unique organization that has the potential to highlight institutional disparities in undergraduate medical education while simultaneously amplifying these disparities as trainees progress through their academic careers because of the importance placed on membership by residency program directors. We urge the national society to take the lead in reforming the selection process, so as not to sustain — or worse, multiply-demographic privilege. We also urge medical schools to collectively lobby for and adopt changes, to avoid complicity in structural racism. While the racial/ethnic diversity of medical schools has modestly improved over the last decade, ${ }^{33}$ much work remains to make the medical school learning environment inclusive and equitable. ${ }^{7,34}$ We recommend collective reform by all schools to catalyze more just access to academic awards and social benefits. We must work together to address these disparities. Equity and inclusion are essential for quality medical education, research, and patient outcomes.

Corresponding Author: Dowin Boatright, MD, MBA, MHS; Department of Emergency Medicine, Yale School of Medicine, New Haven, CT, USA (e-mail: Dowin.Boatright@yale.edu).

\section{Compliance with Ethical Standards:}

Conflict of Interest: The authors declare that they do not have a conflict of interest.

\section{REFERENCES}

1. Nunez-Smith M, Ciarleglio MM, Sandoval-Schaefer T, et al. Institutional variation in the promotion of racial/ethnic minority faculty at US medical schools. Am J Public Health. 2012;102(5):852-858.

2. Ginther DK, Schaffer WT, Schnell J, et al. Race, ethnicity, and NIH research awards. Science. 2011;333(6045):1015-1019.

3. Ginther DK, Haak LL, Schaffer WT, Kington R. Are race, ethnicity, and medical school affiliation associated with NIH RO1 type 1 award probability for physician investigators? Acad Med. 2012;87(11):15161524.

4. Silver JK, Slocum CS, Bank AM, et al. Where are the women? The underrepresentation of women physicians among recognition award recipients from medical specialty societies. PM R. 2017;9(8):804-815.

5. Boatright D, Ross D, O'Connor P, Moore E, Nunez-Smith M. Racial disparities in medical student membership in the Alpha Omega Alpha Honor Society. JAMA Intern Med. 2017;177(5):659-665.

6. Razack S, Risor T, Hodges B, Steinert Y. Beyond the cultural myth of medical meritocracy. Med Educ. 2020;54(1):46-53.

7. Hill KA, Samuels EA, Gross CP, et al. Assessment of the prevalence of medical student mistreatment by sex, race/ethnicity, and sexual orientation. JAMA Intern Med. 2020.

8. How members are chosen. Alpha Omega Alpha Honor Society. https:// www.alphaomegaalpha.org/how.html. Accessed April 6th, 2020.

9. Charting outcomes in the match: US allopathic seniors. National Resident Matching Program; 2018. https://www.nrmp.org/wp-content/ uploads/2018/06/Charting-Outcomes-in-the-Match-2018-Seniors.pdf. Accessed 12 Oct 2018.

10. DeCroff CM, Mahabir RC, Zamboni WA. The impact of alpha omega alpha membership on successfully matching to residency. Plast Reconstr Surg. 2010;126(2):113e-115e.

11. Interactive charting outcomes in the match. National Resident Matching Program. http://www.nrmp.org/interactive-charting-outcomes-in-thematch/. Accessed October 12th, 2018. 
12. van Balen B, van Arensbergen, P., van der Weijden, I. Determinants of sucess in academic careers. Higher Education Policy.25(3):313-334.

13. Dugger RA, El-Sayed AM, Dogra A, Messina C, Bronson R, Galea S. The color of debt: racial disparities in anticipated medical student debt in the United States. PLoS One. 2013;8(9):e74693.

14. Cooper LA, Roter DL, Johnson RL, Ford DE, Steinwachs DM, Powe NR. Patient-centered communication, ratings of care, and concordance of patient and physician race. Ann Intern Med. 2003;139(11):907-915.

15. Institute of Medicine. Unequal treatment: confronting racial and ethnic disparities in health care. https://www.nap.edu/catalog/10260/un equal-treatment-confronting-racial-and-ethnic-disparities-in-healthcare. Accessed 21 Aug 020

16. Hassouneh D, Lutz KF, Beckett AK, Junkins EP, Horton LL. The experiences of underrepresented minority faculty in schools of medicine. Med Educ Online. 2014;19:24768.

17. Osseo-Asare A, Balasuriya L, Huot SJ, et al. Minority resident physicians' views on the role of race/ethnicity in their training experiences in the workplace. JAMA Network Open. 2018;1(5).

18. Umbach $\mathbf{P}$. The contribution of faculty of color to undergraduate education. Research in Higher Education. 2006;47:317-345.

19. Hofstra B, Kulkarni VV, Munoz-Najar Galvez S, He B, Jurafsky D, McFarland DA. The Diversity-Innovation Paradox in Science. Proc Natl Acad Sci USA. 2020;117(17):9284-9291.

20. Hoppe TA, Litovitz A, Willis KA, et al. Topic choice contributes to the lower rate of NIH awards to African-American/black scientists. Sci Adv 2019;5(10):eaaw7238.

21. Pololi LH, Evans AT, Gibbs BK, Krupat E, Brennan RT, Civian JT. The experience of minority faculty who are underrepresented in medicine, at 26 representative U.S. medical schools. Acad Med. 2013;88(9):13081314.

22. Byyny RL, Martinez D, Cleary L, et al. Alpha Omega Alpha Honor Medical Society: a commitment to inclusion, diversity, equity, and service in the profession of medicine. Acad Med. 2019.

23. Miller J, Ross JS, Wilenzick M, Mello MM. Sharing of clinical trial data and results reporting practices among large pharmaceutical companies: cross sectional descriptive study and pilot of a tool to improve company practices. BMJ. 2019;366:14217.

24. Hess D. Social reporting and new governance regulation: the prospects of achieving corporate accountability through transparency. Business Ethics Quarterly. 2007;17(3):453-476.
25. Phelan SM, Burke SE, Hardeman RR, et al. Medical school factors associated with changes in implicit and explicit bias against gay and lesbian people among 3492 graduating medical students. J Gen Intern Med. 2017;32(11):1193-1201.

26. van Ryn M, Hardeman R, Phelan SM, et al. Medical school experiences associated with change in implicit racial bias among 3547 students: a medical student CHANGES study report. $J$ Gen Intern Med. 2015;30(12): 1748-1756.

27. Teherani A, Hauer KE, Fernandez A, King TE Jr, Lucey C. How smal differences in assessed clinical performance amplify to large differences in grades and awards: a cascade with serious consequences for students underrepresented in medicine. Acad Med. 2018.

28. Rojek AE, Khanna R, Yim JWL, et al. Differences in narrative language in evaluations of medical students by gender and under-represented minority status. J Gen Intern Med. 2019;34(5):684-691.

29. Ross DA, Boatright D, Nunez-Smith M, Jordan A, Chekroud A, Moore EZ. Differences in words used to describe racial and gender groups in Medical Student Performance Evaluations. PLoS One. 2017;12(8):e0181659.

30. Low D, Pollack SW, Liao ZC, et al. Racial/ethnic disparities in clinical grading in medical school. Teach Learn Med. 2019:1-10.

31. Teherani A, Harleman E, Hauer KE, Lucey C. Toward creating equity in awards received during medical school: strategic changes at one institution. Acad Med. 2020.

32. Lynch G, Holloway T, Muller D, Palermo AG. Suspending student selections to Alpha Omega Alpha Honor Medical Society: how one school is navigating the intersection of equity and wellness. Acad Med. 2019.

33. Boatright DH, Samuels EA, Cramer L, et al. Association between the Liaison Committee on Medical Education's diversity standards and changes in percentage of medical student sex, race, and ethnicity. JAMA. 2018;320(21):2267-2269.

34. Ackerman-Barger $\mathbf{K}$, Boatright $\mathbf{D}$, Gonzalez-Colaso $\mathbf{R}$, Orozco $\mathbf{R}$, Latimore D. Seeking inclusion excellence: understanding racial microaggressions as experienced by underrepresented medical and nursing students. Acad Med. 2020;95(5):758-763.

Publisher's Note: Springer Nature remains neutral with regard to jurisdictional claims in published maps and institutional affiliations. 